\title{
The Influence of Heat Treatment on the Caustic Etching Behaviour of the Automotive AA6111 Alloy
}

\author{
Abdelhadi Abouarkoub1, George Thompson², Xiaorong Zhou², Geoffrey Scamans ${ }^{3}$ \\ ${ }^{1}$ The Libyan Petroleum Institute, Tripoli, Libya \\ ${ }^{2}$ School of Materials, The University of Manchester, Manchester, UK \\ ${ }^{3}$ Innoval Technology Limited, Banbury, UK \\ Email: Abdalhadi_aboargoub@yahoo.com
}

How to cite this paper: Abouarkoub, A., Thompson, G., Zhou, X.R. and Scamans, G. (2016) The Influence of Heat Treatment on the Caustic Etching Behaviour of the Automotive AA6111 Alloy. Journal of Minerals and Materials Characterization and Engineering, 4, 364-379.

http://dx.doi.org/10.4236/jmmce.2016.46030

Received: August 28, 2016

Accepted: November 18, 2016

Published: November 21, 2016

Copyright $\odot 2016$ by authors and Scientific Research Publishing Inc. This work is licensed under the Creative Commons Attribution International License (CC BY 4.0).

http://creativecommons.org/licenses/by/4.0/

\begin{abstract}
The caustic etching behaviour of the automotive AA6111 alloy with different aging conditions that simulate the various levels of heat input within the heat affected zone during the welding heating cycles has been investigated. The alloy dissolution rate was found to substantially increase with the pre-aging temperature, which enhances precipitation of the cathodic $Q$-phase and results in depletion of the alloy solid solution in magnesium and silicon. On the other hand, enhancing the kinetics of precipitation at high temperatures induces a more uniform distribution the $Q$-phase precipitates, which minimizes the potential difference between the interiors and boundaries of the adjacent grains. This was observed to reduce the severity of the surface topography developed by subsequent caustic etching surface pre-treatment.
\end{abstract}

\section{Keywords}

Caustic Etching, Heat Treatment, AA6111, Q-Phase

\section{Introduction}

In the automotive industry, chemical surface pre-treatment of the aluminium alloy body panels in hot caustic soda solutions is one of the most critical steps in the coating application process [1]. In addition to the improvement in adhesion of the organic coating, alkaline etching is also known to be very effective in removing the sub-surface, disturbed layers introduced during cold and hot rolling of the aluminium alloys, which may alter their surface corrosion properties [2] [3] [4] [5] [6]. Further, as a part of the multistep chemical pre-treatment, desmutting in dilute acidic solutions is commonly 
used to remove the black smut, intermetallics, insoluble oxides and residual solutes left on surface by alkaline etching [2]-[7].

For unalloyed aluminum, after dissolution of the air-formed film during alkaline etching, the etching rate of the aluminum substrate is dependent on the dissolution and growth rate of a thin residual alumina film formed at the aluminum surface. This process involves migration of the $\mathrm{Al}^{3+}$ cations to the alumina film/solution interface, ejection of $\mathrm{Al}^{3+}$ ions to the solution and migration of the $\mathrm{O}^{2-}$ ions to alloy/film interface [8]. However, the dissolution behaviour of aluminum in hot alkaline solutions can be significantly affected by the presence, type and distribution of alloying elements. For example, caustic etching of magnesium-containing aluminum alloys is known to enrich their outer alumina film with magnesium [9] [10], which is related to the faster migration of the magnesium species relative to that of $\mathrm{Al}^{3+}$ ions and to the higher stability of the magnesium oxides/hydroxides in strong alkaline environments. This phenomenon is reported to reduce the dissolution rate of the underlying aluminum substrates [11] [12]. Previous studies have also shown that the caustic etching rate decrease with the silicon contents [8], and significantly increase with the copper contents [13] of the aluminum alloys.

Further, the behaviour of aluminum alloys in hot alkaline solutions is also known to be strongly dependent on the chemical composition, electrochemical activity, density and distribution of the various aging phases and intermetallic particles [5] [8]. Therefore, the dissolution rate and surface topography developed after alkaline treatment are expected to significantly vary with the aging condition of the automotive, heat treatable aluminum alloys. Such variation can be more significant in the vicinity of the welding joints, where the heat-affected zone of the heat-treatable aluminum alloys normally consists of several regions with various microstructural, mechanical and electrochemical properties.

In the present study, the influence of heat treatment on the caustic etching behaviour of the AA6111 alloy, which is one of the most promising Al-Mg-Si-Cu automotive alloys for outer panel applications in Europe and North America, is investigated. The investigation was undertaken first by performing laboratory heat treatments of the AA6111 alloy at different aging temperatures that simulate the various levels of heat input within the heat affected zone during the welding heating cycles. The caustic etching behaviour of the AA6111 alloy at different aging conditions was then investigated.

\section{Experimental}

The material investigated in this study was a commercial AA6111-T4P automotive alloy, with the chemical composition listed in Table 1 . The alloy was provided in the form of $0.9 \mathrm{~mm}$ thick cold rolled sheet, which had been pre-aged at $85^{\circ} \mathrm{C}$ for 5 hours and then stored at room temperature for more than three years. In order to study the influence of prolonged natural aging on the caustic etching behaviour of the AA6111T4P alloy, two sets of samples were prepared. Samples of the first set were left in the as-received condition (T4P +3 years storage, hereafter referred to as T4PNA), where as 
Table 1. The composition (wt\%) of the AA6111 alloy.

\begin{tabular}{ccccccc}
\hline $\mathrm{Si}$ & $\mathrm{Mg}$ & $\mathrm{Cu}$ & $\mathrm{Fe}$ & $\mathrm{Mn}$ & $\mathrm{Ti}$ & $\mathrm{Al}$ \\
\hline 0.60 & 0.70 & 0.71 & 0.24 & 0.22 & 0.06 & Bal. \\
\hline
\end{tabular}

all samples of the second set were solution treated at $550^{\circ} \mathrm{C}$ for $22 \mathrm{~min}$ and water quenched to room temperature (ST temper). Both sets of samples were then subjected to aging at $180^{\circ} \mathrm{C}, 250^{\circ} \mathrm{C}, 310^{\circ} \mathrm{C}$, and $410^{\circ} \mathrm{C}$ in a laboratory electrical furnace for 30 minutes, followed by air cooling. The age hardening precipitation of the AA6111-T4P and AA6111-ST alloys during these heat treatments was extensively investigated and described in detail elsewhere [14].

Caustic etching of the differently aged samples of the AA6111 alloy was undertaken by a continuous immersion for $5 \mathrm{~min}$ of in $10 \mathrm{wt} \% \mathrm{NaOH}$ solution at $60^{\circ} \mathrm{C}$, followed by $15 \mathrm{~s}$ room temperature desmutting in $25 \mathrm{vol} \% \mathrm{HNO}_{3}$. The etching rate, expressed as the weight loss per $\cdot \mathrm{cm}^{2}$, was then calculated using the following Equation.

$$
w=\left(1-\frac{w_{1}}{w_{0}}\right) \cdot\left(\frac{\rho \cdot h \cdot 10^{3}}{2}\right)\left(\mathrm{mg} \cdot \mathrm{cm}^{-2}\right)
$$

where $w_{0}$ and $w_{1}$ are the weights in grams of the samples before and after etching, $\rho$ is the alloy density (assumed to be equal to the density of aluminium $=2.7 \mathrm{~g} \cdot \mathrm{cm}^{-3}$ ) and $\mathrm{h}$ is the sample thickness $(0.09 \mathrm{~cm})$.

Following caustic etching and desmutting, surface characterization of the heat-treated samples of the AA6111 alloy was conducted using Zeiss EVO scanning electron microscope, equipped with INCA FETX3 EDX analyzer.

\section{Results}

The etching behaviour of the AA6111-T4PNA and AA6111-ST alloys in hot sodium hydroxide solution as a function of the aging temperature is shown in Figure 1. It is obvious that the dissolution rate of the heat treated alloys was enhanced, relative to the untreated condition.

The backscattered electron micrographs in Figure 2 show the caustic etched and desmutted surface of the AA6111-T4PNA alloy in the as-received condition and following aging treatments at various temperatures. In general, all etched surfaces exhibited a scalloped topography, which is the characteristic of an aluminium surface uniformly etched in alkaline solutions [15]. The significant scalloping of the etched surfaces is an indication to the considerable amounts of the $\alpha$-intermetallic particles, which have been trenched and lost to the solution during the etching process, leaving cavities at their original locations. However, the high population density of the $\alpha$-intermetallic particles revealed around the scalloped depressions indicates that several new intermetallics were exposed on the surface during caustic etching. Scalloping of the etched surface by exposing and/or trenching of the underlying intermetallic particles after selective dissolution of the sub-surface layer of the AA6111-T4PNA alloy was evident even 


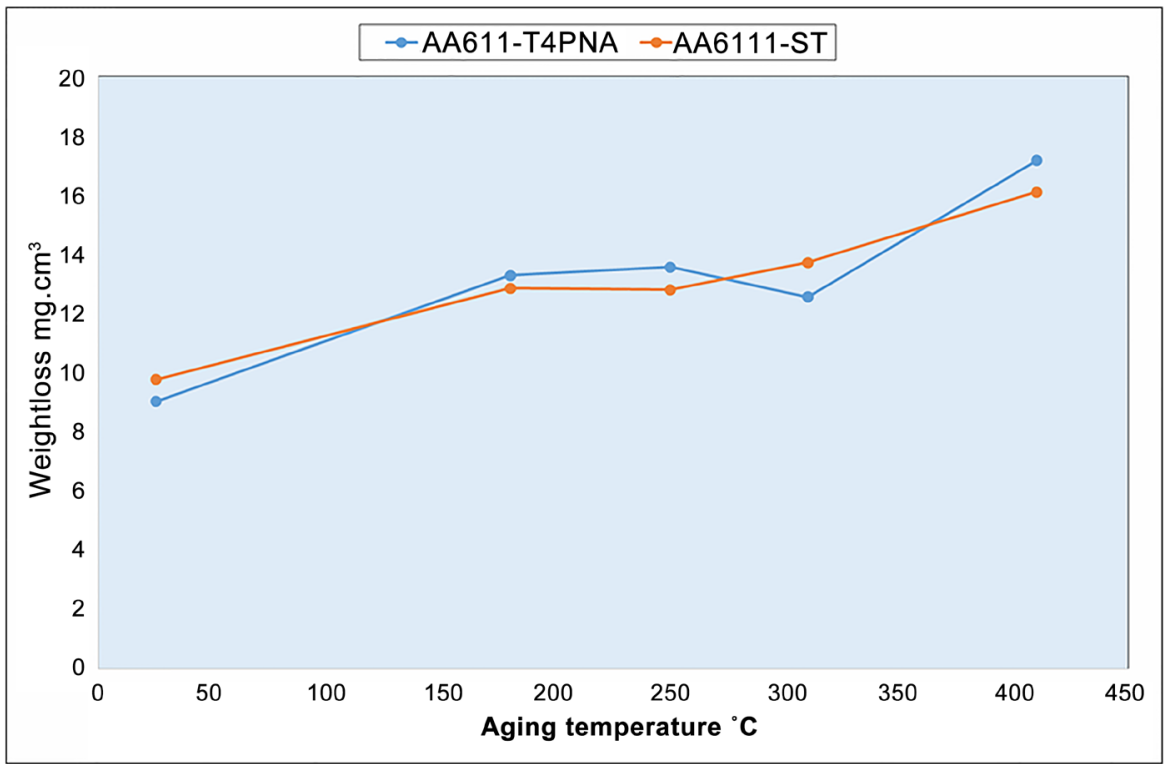

Figure 1. The weight loss as a function of the artificial aging temperature of the AA6111T4PNA and AA6111-ST alloys after 5 min of etching in a $10 \mathrm{wt} \% \mathrm{NaOH}$ solution at $60^{\circ} \mathrm{C}$ followed by a 15 s room temperature desmutting in 25 vol\% $\mathrm{HNO}_{3}$.

after short-periods of alkaline etching, as shown in Figure 3. Solution treatment prior to artificial aging treatment was found to have no effect on the general scalloped morphology developed by alkaline etching of the AA6111-ST alloy, as shown in Figure 4.

At increased magnifications, the scanning electron microscope imaging shows that the etching rate at the grain boundary regions of the AA6111 alloy is dependent on the alloy aging condition. In the as-quenched (ST) condition, where no grain boundary phases exist, the etching rate of the alloy matrix was uniform, as shown in Figure 5(a), Figure 5(b). Precipitation of the Q-phase precursors at the grain boundaries of the AA6111-T4PNA alloy during the prolonged natural aging resulted in a slight variation in the etching rate at these regions relative to the surrounding matrix. Consequently, the grain boundaries of the AA6111-T4PNA alloy were slightly revealed after alkaline etching, as shown in Figure 6(a), Figure 6(b). Increasing the intergranular precipitation kinetics at $180^{\circ} \mathrm{C}$, for both the AA6111-ST and AA6111-T4PNA alloys, enhances the dissolution rate at the grain boundary regions (Figure 5(c), Figure 5(d) and Figure $6(\mathrm{c})$, Figure $6(\mathrm{~d})$ ). At the peak-aging condition, $30 \mathrm{~min}$ at $250^{\circ} \mathrm{C}$, the dissolution rate along the grain boundary regions was more significant, especially for the AA6111T4PNA alloy, resulting in the formation of deep grooves within which intergranular precipitates remnants were observed (Figure 5(e), Figure 5(f) and Figure 6(e), Figure $6(\mathrm{f})$ ). At the over-aging condition, $30 \mathrm{~min}$ at $310^{\circ} \mathrm{C}$, the dissolution rate along the grain boundary regions was considerably reduced compared with the peak-aging condition (Figures 5(g), Figure 5(h) and Figure 6(g), Figure 6(h)). Over-aging at $410^{\circ} \mathrm{C}$ resulted in a more uniform dissolution of alloy surrounding the matrix and intergranular precipitates, including the precipitate free zones along the grain boundaries (Figure 5(i), Figure 5(j) and Figure 6(i), Figure 6(j)). 


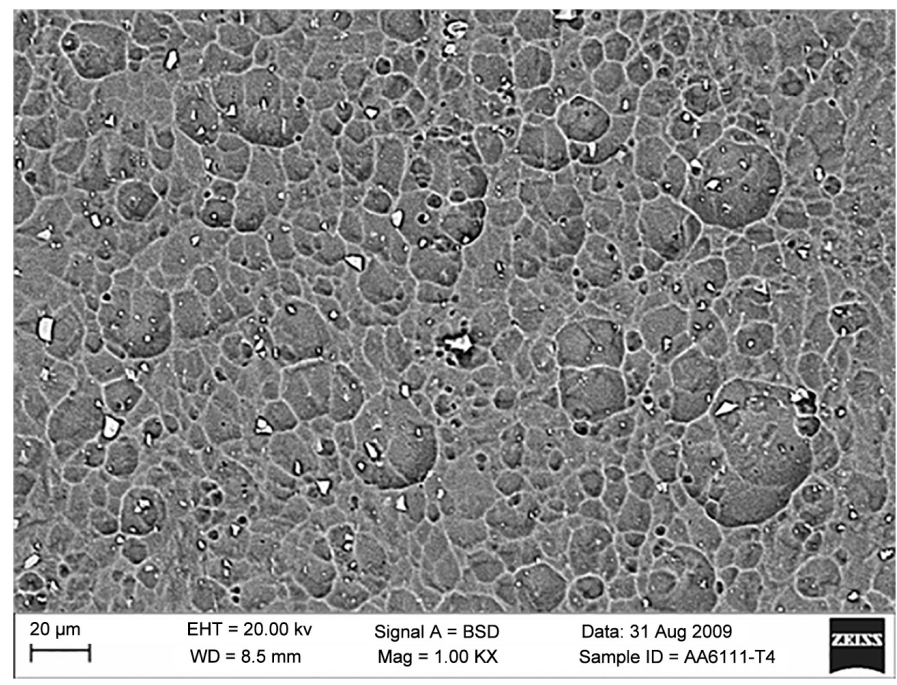

(a)

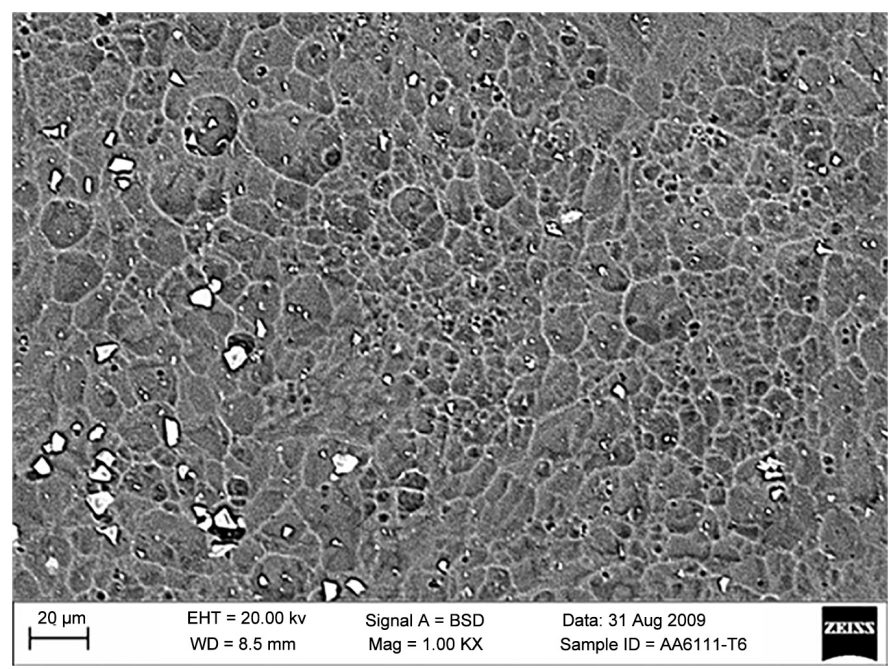

(b)

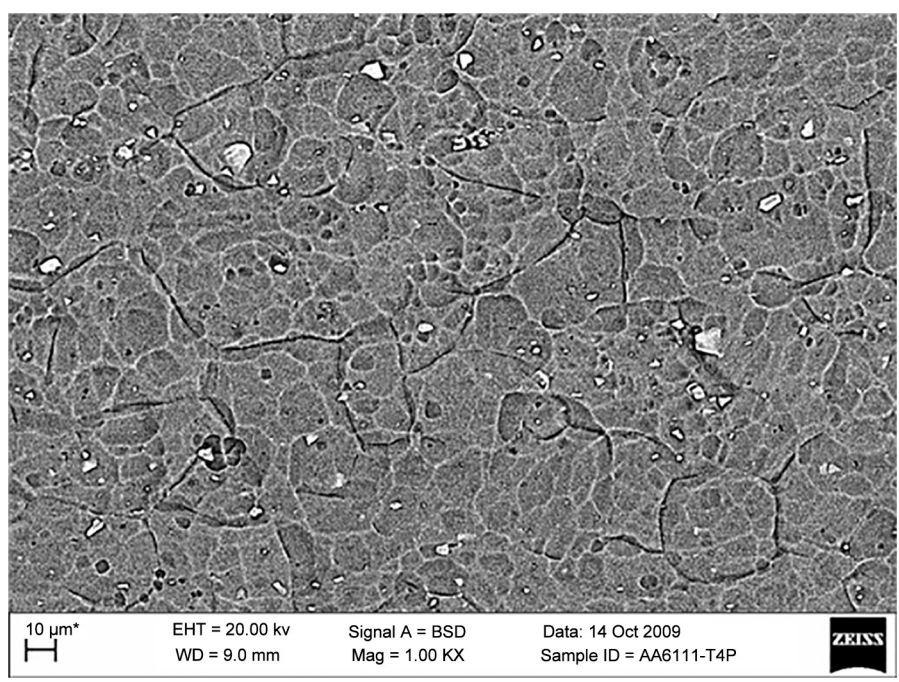

(c) 


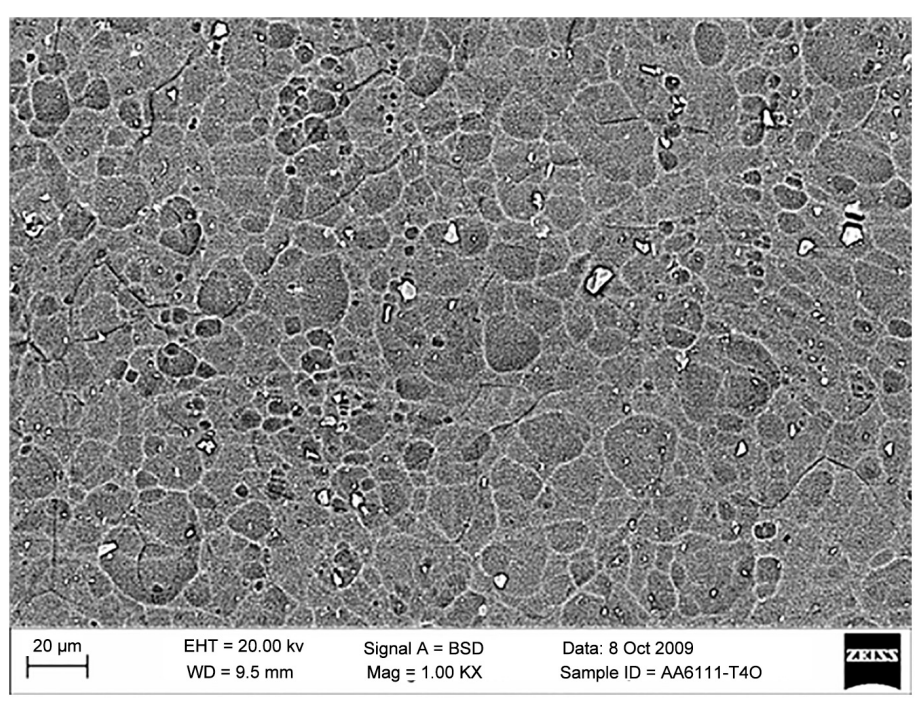

(d)

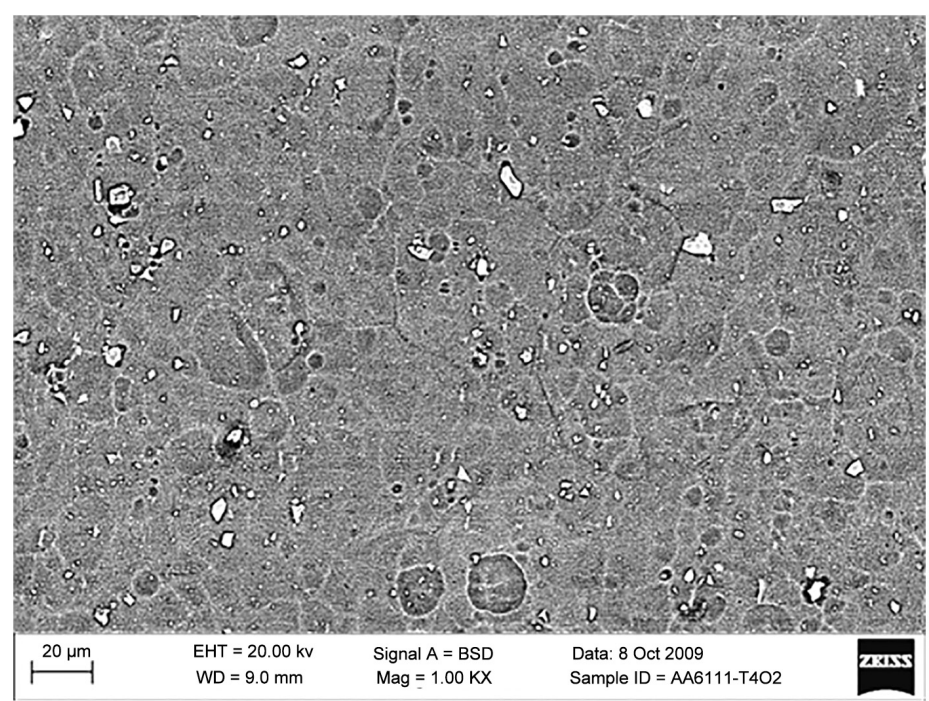

(e)

Figure 2. Backscattered electron micrographs of different aging tempers of the AA6111-T4PNA alloy after $300 \mathrm{sec}$ of etching in $10 \mathrm{wt} \% \mathrm{NaOH}$ solution at $60^{\circ} \mathrm{C}$ followed by $15 \mathrm{sec}$ room temperature desmutting in 25 vol\% $\mathrm{HNO}_{3}$; (a) as-received; (b) under-aged at $180^{\circ} \mathrm{C}$ for $30 \mathrm{~min}$; (c) peak-aged at $250^{\circ} \mathrm{C}$ for $30 \mathrm{~min}$; (d) over-aged at $310^{\circ} \mathrm{Cfor} 30 \mathrm{~min}$ and (e) highly over-aged at $410^{\circ} \mathrm{C}$ for $30 \mathrm{~min}$.

\section{Discussion}

The etching rates of the AA6111-ST and AA6111-T4PNA alloys in hot sodium hydroxide solution were observed to increase with the alloys pre-aging temperature. This can be related to the precipitation of solute atoms, in particular, magnesium and silicon atoms, during the aging treatment. Depletion of the AA6111-ST and AA6111-T4PNA alloys solid-solutions in these elements is expected to increase their dissolution rates in sodium hydroxide solution, which agrees with previous findings [8] [11] [12]. 

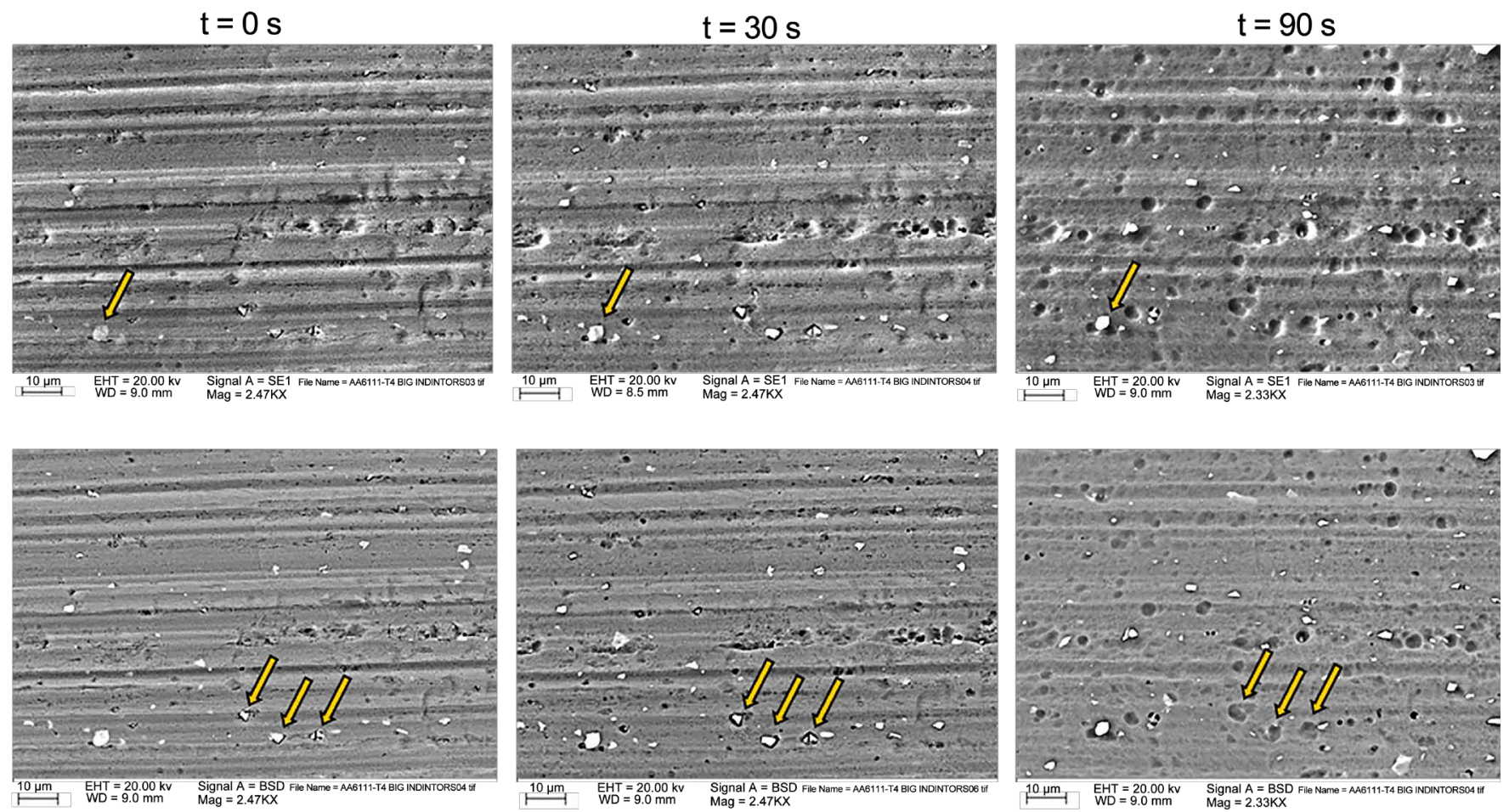

Figure 3. Scanning electron and backscattered micrographs shown the $\alpha$-intermetallic particles at the surface of the AA6111-T4PNA alloy before and after increased etching times $(\mathrm{t})$ in $10 \mathrm{wt} \% \mathrm{NaOH}$ solution at $60^{\circ} \mathrm{C}$.

On the other hand, being an electrochemical reaction in nature, the dissolution rate of the AA6111 alloy in sodium hydroxide solution must be also influenced by the electrochemical activity and population density of the aging phases and intermetallic particles.

In the AA6111 alloy, the main second phases are the $\alpha-\mathrm{Al}(\mathrm{Fe}, \mathrm{Mn}, \mathrm{Cu}, \mathrm{Cr})_{\mathrm{X}} \mathrm{Si}_{\mathrm{Y}}$ intermetallic particles and the family of the $Q-(\mathrm{Al}-\mathrm{Mg}-\mathrm{Si}-\mathrm{Cu})$ aging precipitates. According to previous studies on the dissolution rates of the various intermetallic particles in the aluminum alloys in sodium hydroxide solution [8] [16] [17], the dissolution rate of the silicon-containing, $\alpha$-intermetallic particles and $Q$-aging precipitates is low compared with the alloys matrix. Further, the dissolution rate of the magnesium-containing $Q$ aging precipitates in sodium hydroxide solutions can be further reduced due to the lower solubility of the magnesium hydroxide " $\mathrm{Mg}(\mathrm{OH})_{2}$ " in alkaline environments [18].The stability of magnesium-containing aging phases, such as the $\mathrm{Al}_{2} \mathrm{CuMg}$ " $\mathrm{S}$ " and $\mathrm{Mg}_{2} \mathrm{Si}$ “ $\beta$ ” phases, in sodium hydroxide solutions has been previously reported [2] [5] [19] [20].

In agreement with the Literature, the scanning electron microscopy investigation in the present work shows that caustic etching treatment resulted in a preferential dissolution of the AA6111 alloy matrix in the vicinities of the iron-containing $\alpha$-intermetallics and copper-containing $Q$-phase precipitates. Therefore, it can be predicted that the dissolution rate of the heat treated AA6111 alloy in sodium hydroxide solution is mainly determined by the population density of the $\alpha$-intermetallics and the $Q$-phase 


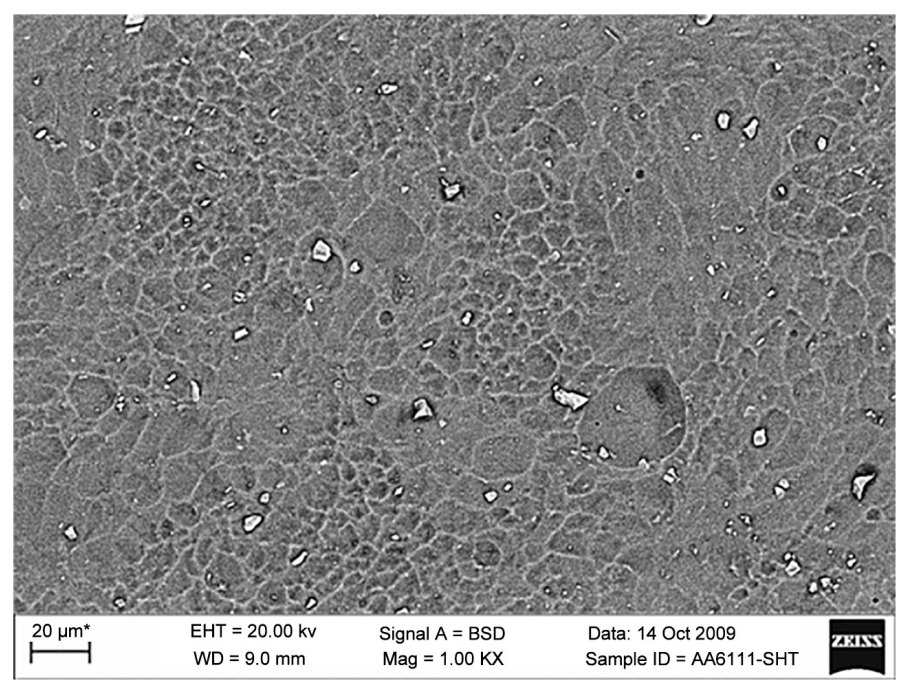

(a)

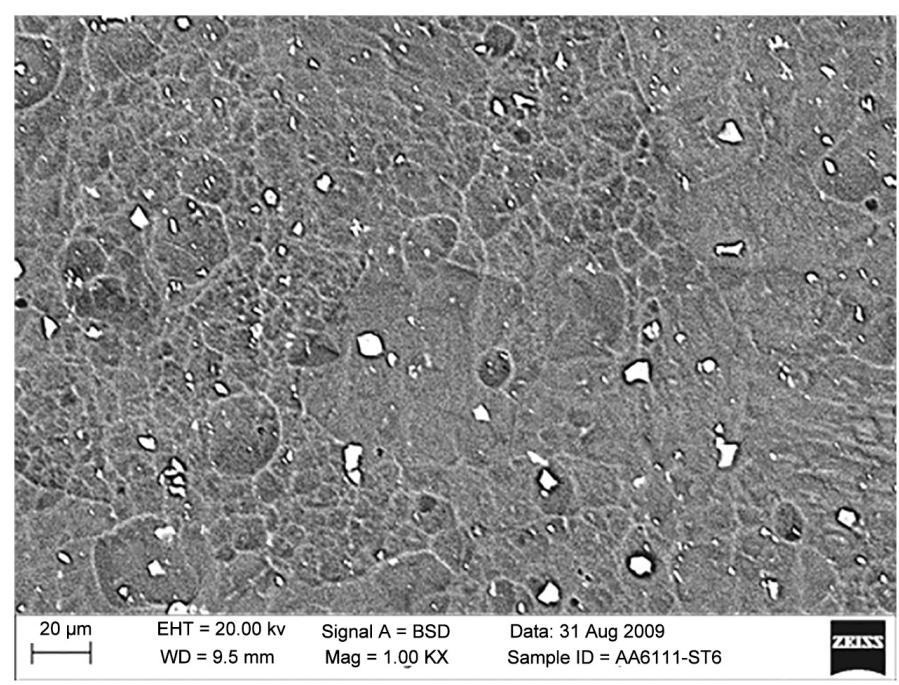

(b)

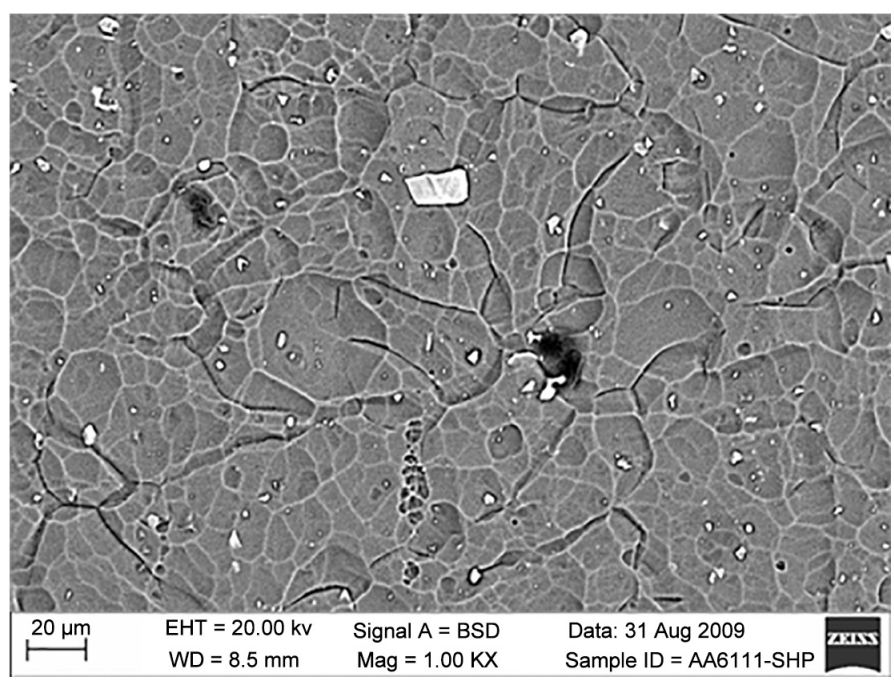

(c) 


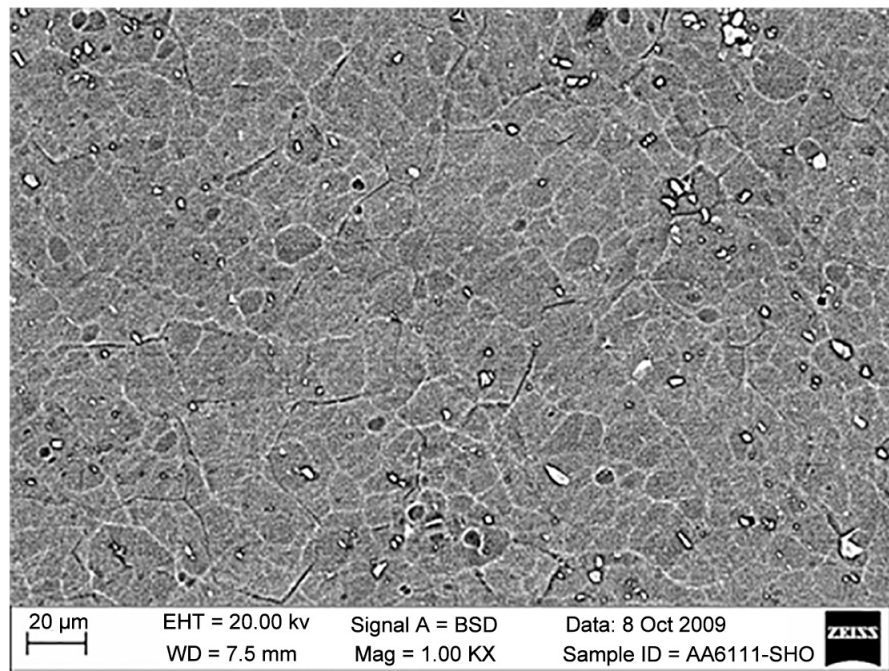

(d)

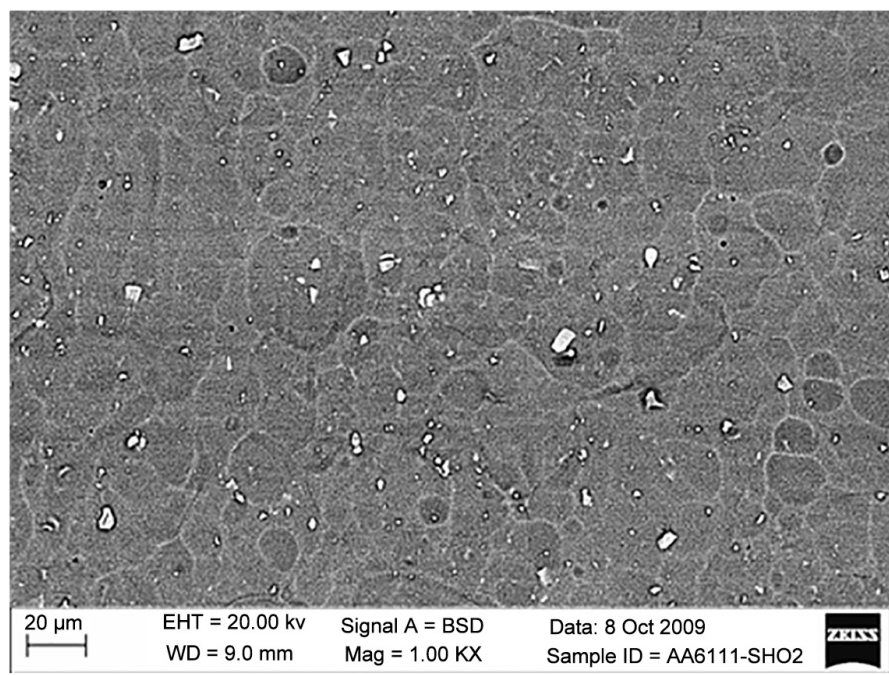

(e)

Figure 4. Backscattered electron micrographs of different aging tempers of theAA6111-ST alloy after $300 \mathrm{sec}$ of etching in $10 \mathrm{wt} \%$ $\mathrm{NaOH}$ solution at $60^{\circ} \mathrm{C}$ followed by $15 \mathrm{sec}$ room temperature desmutting in 25 vol\% HNO3; (a) as-quenched; (b) under-aged at $180^{\circ} \mathrm{C}$ for $30 \mathrm{~min}$; (c) peak-aged at $250^{\circ} \mathrm{C}$ for $30 \mathrm{~min}$; (d) over-aged at $310^{\circ} \mathrm{C}$ for $30 \mathrm{~min}$ and (e) highly over-aged at $410^{\circ} \mathrm{C}$ for $30 \mathrm{~min}$.

precipitates, at which the kinetics of the hydrogen evolution cathodic reaction are enhanced [8]. However, solution treatment at $550^{\circ} \mathrm{C}$ and subsequent artificial aging up $410^{\circ} \mathrm{C}$, employed in the present work, are not expected to induce significant modifications in the size, distribution and chemical composition of $\alpha$-intermetallic particles in the AA6111 alloy [21] [22]. On the contrary, the population density, size, stoichiometry and, thus, the electrochemical activities of the $Q$-aging precipitates are strongly dependent on the alloy thermal history. Therefore, assuming that all the investigated tempers of the AA6111-ST and AA6111-T4PNA alloys have similar or comparable 


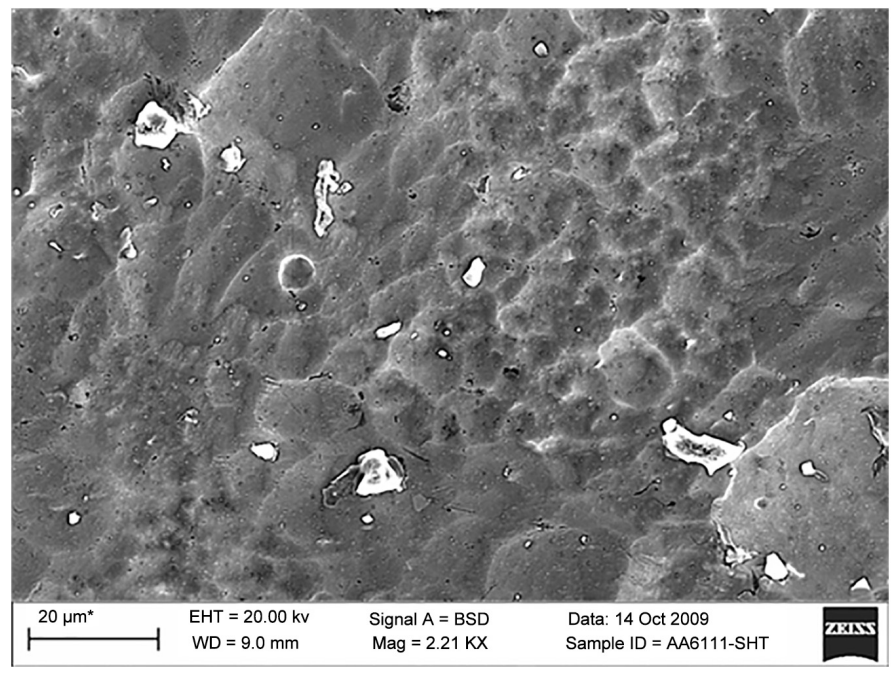

(a)

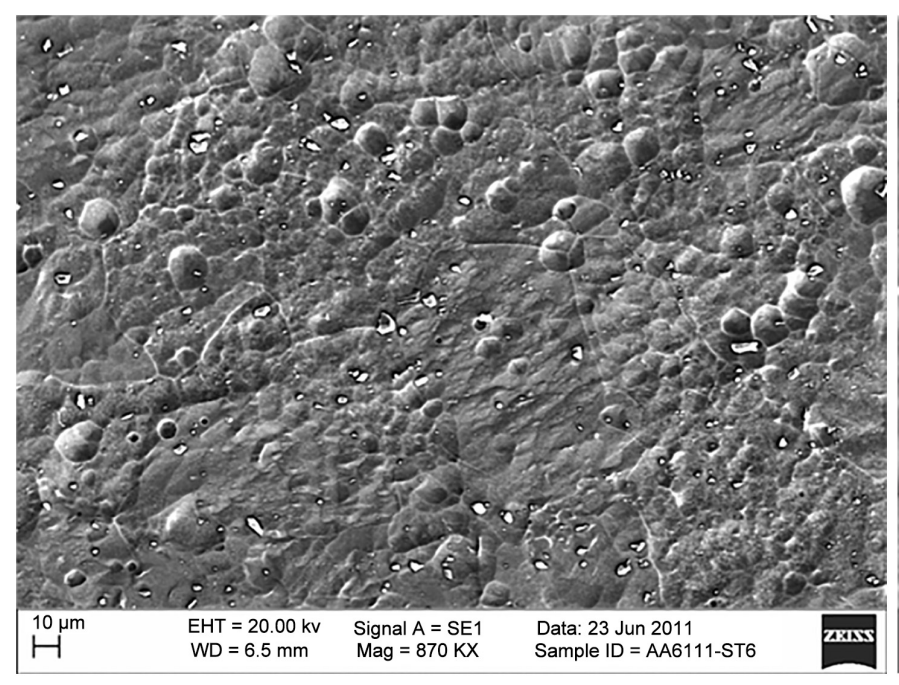

(c)

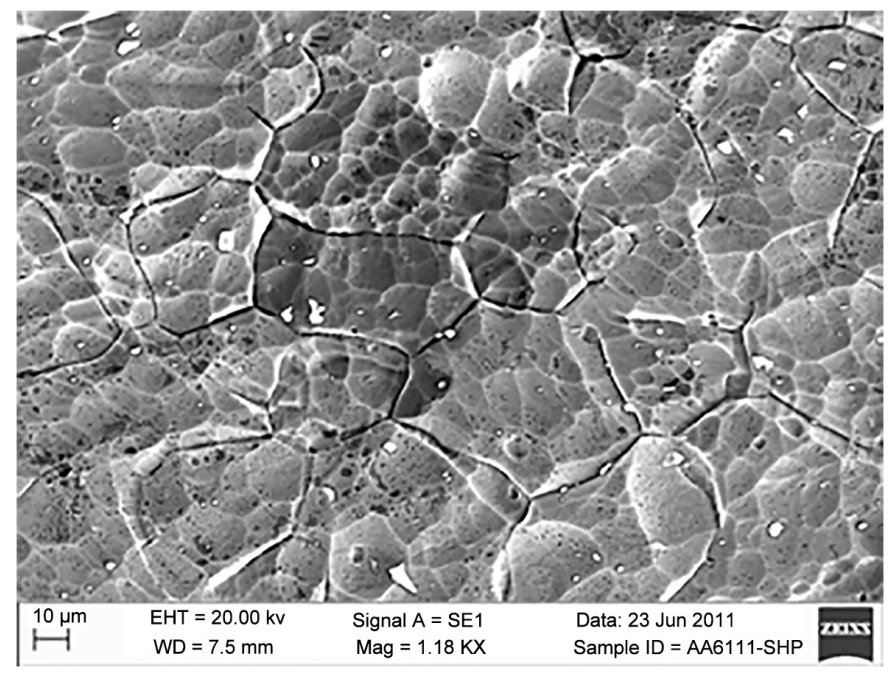

(e)

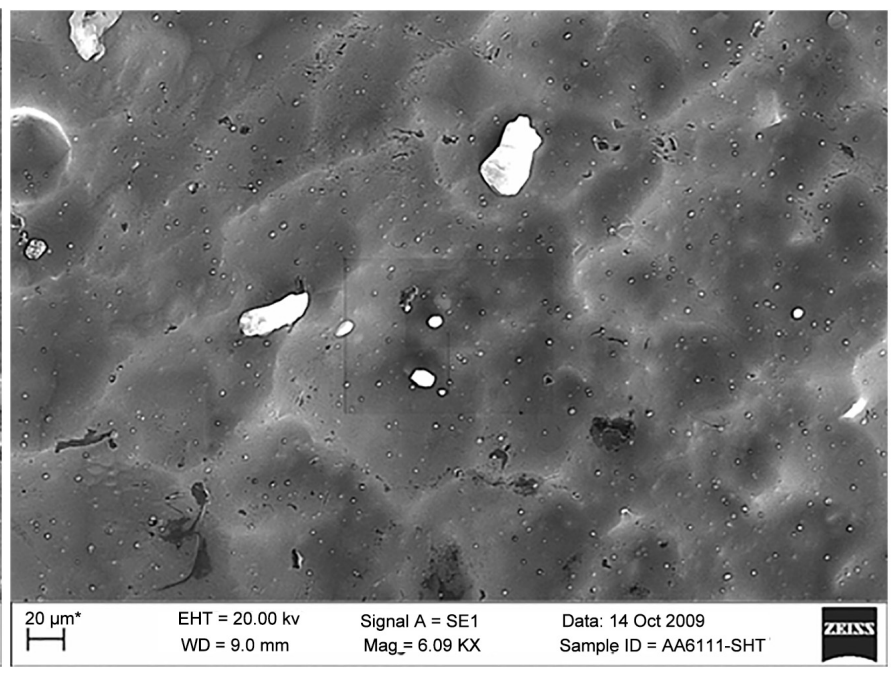

(b)

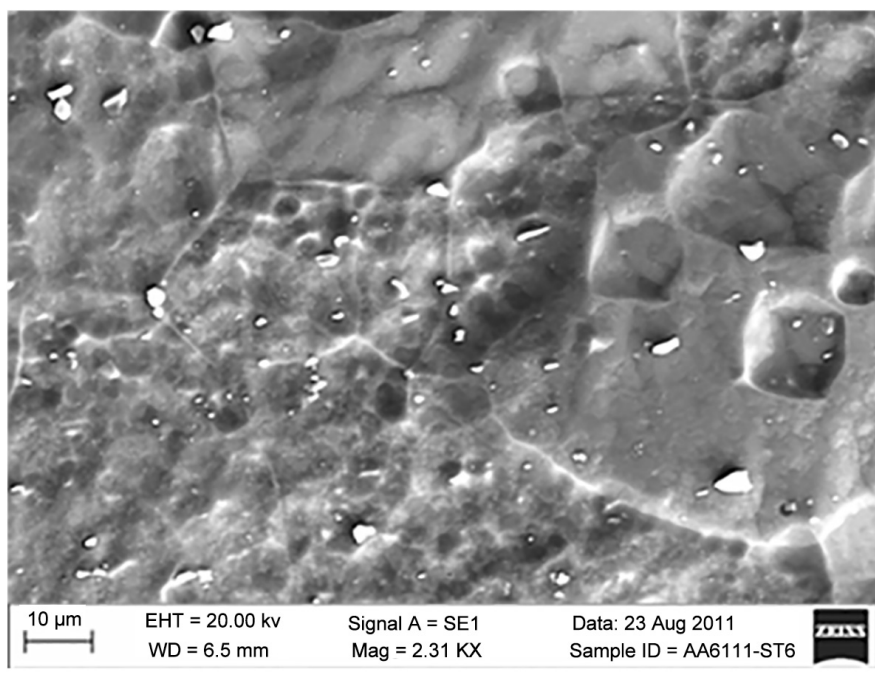

(d)

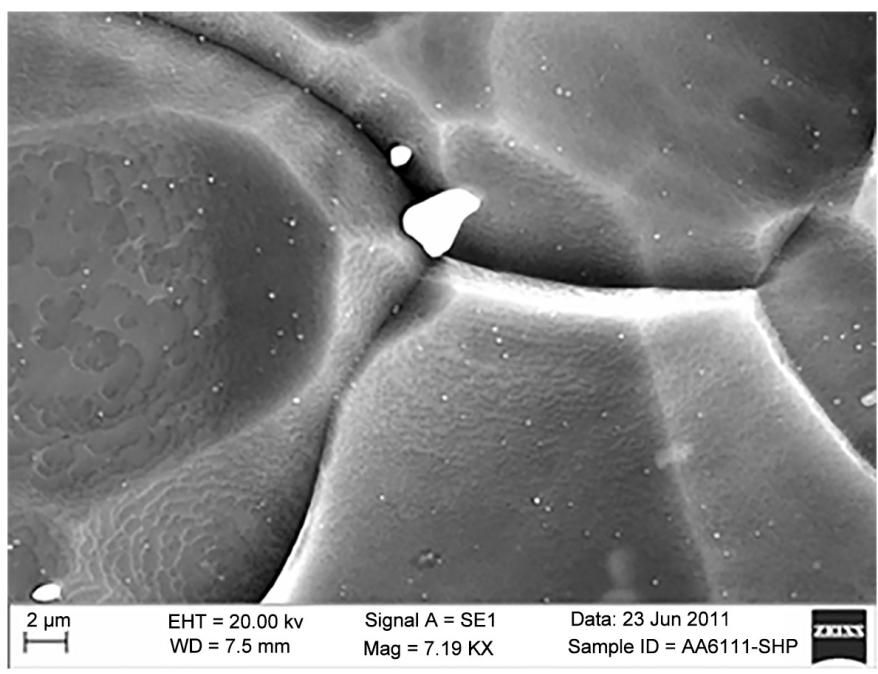

(f) 


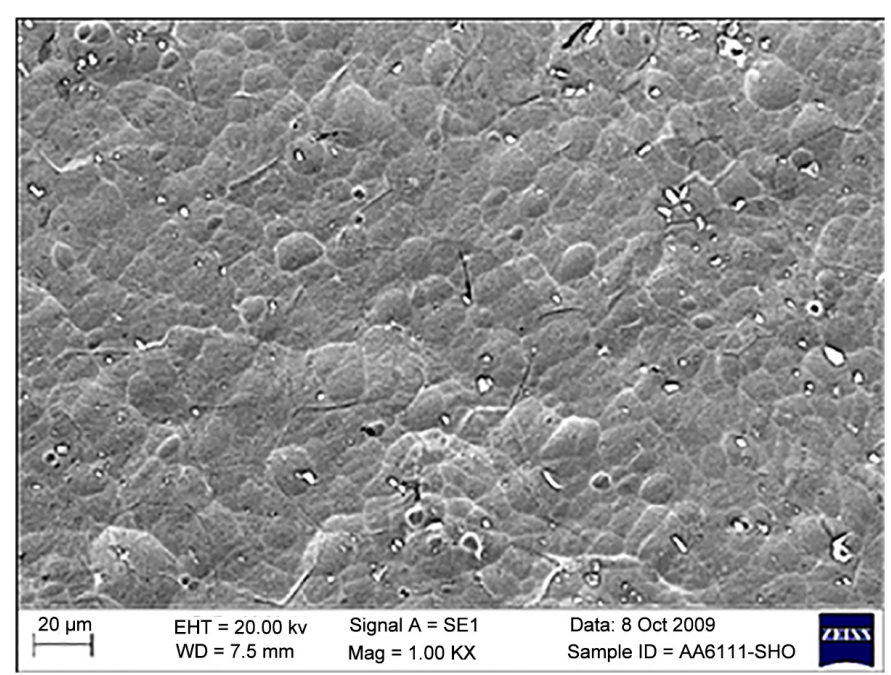

(g)

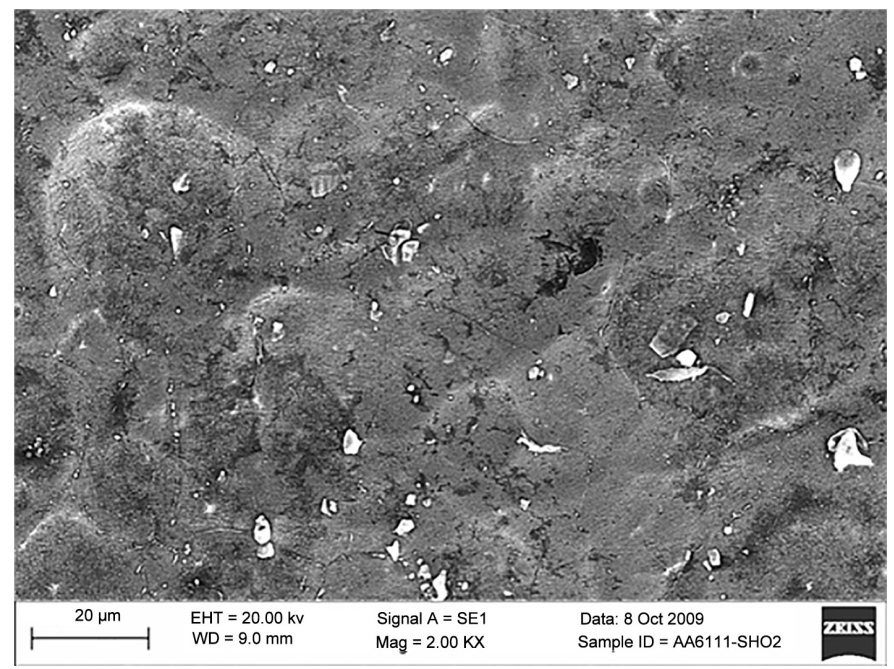

(i)

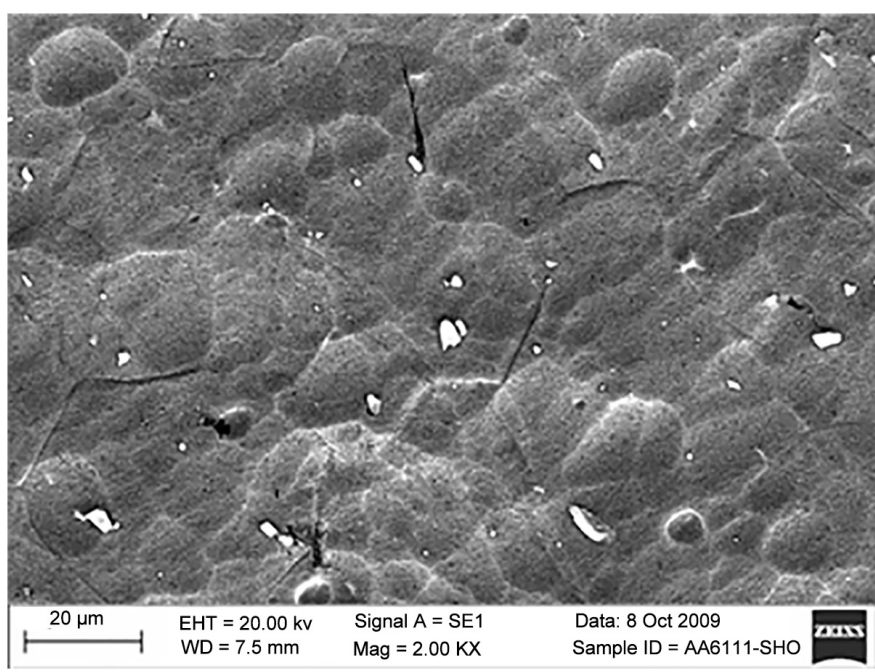

(h)

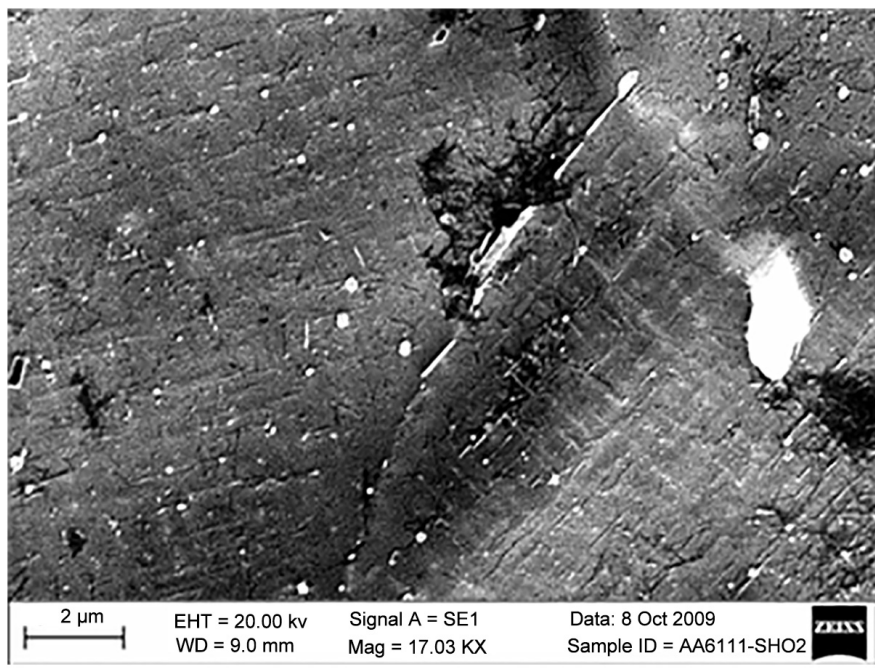

(j)

Figure 5. Scanning electron micrographs of different aging tempers of theAA6111-ST alloy after 300 sec of etching in 10 wt\% NaOH solution at $60^{\circ} \mathrm{C}$ followed by $15 \mathrm{sec}$ room temperature desmutting in 25 vol\% $\mathrm{HNO}_{3}$; (a), (b) as-quenched; (c), (d) under-aged at $180^{\circ} \mathrm{C}$ for $30 \mathrm{~min}$; (e), (f) peak-aged at $250^{\circ} \mathrm{C}$ for $30 \mathrm{~min}$; (g), (h) over-aged at $310^{\circ} \mathrm{C}$ for $30 \mathrm{~min}$; and (i), (j) highly over-aged at $410^{\circ} \mathrm{C}$ for $30 \mathrm{~min}$.

amounts of $\alpha$-intermetallic particles on their surface, the increase in the caustic etching rate of these alloys with the aging condition can be related to the increased population density of the cathodic $Q$-phase, as well as, to the increased depletion of the alloys solid solution in magnesium and silicon.

Further, the results of the present study suggest that the surface topography developed after alkaline etching of the AA6111 alloy is strongly dependent on the distribution and electrochemical activity of the $Q$-phase precipitates. For example, the homogenous distribution of high population density of the $Q$-phase precipitate in the matrix of the highly over-aged AA6111 alloy (aged at $410^{\circ} \mathrm{C}$ ) resulted in a uniform etching of the alloy in sodium hydroxide solution. On the contrary, the less homoge- 


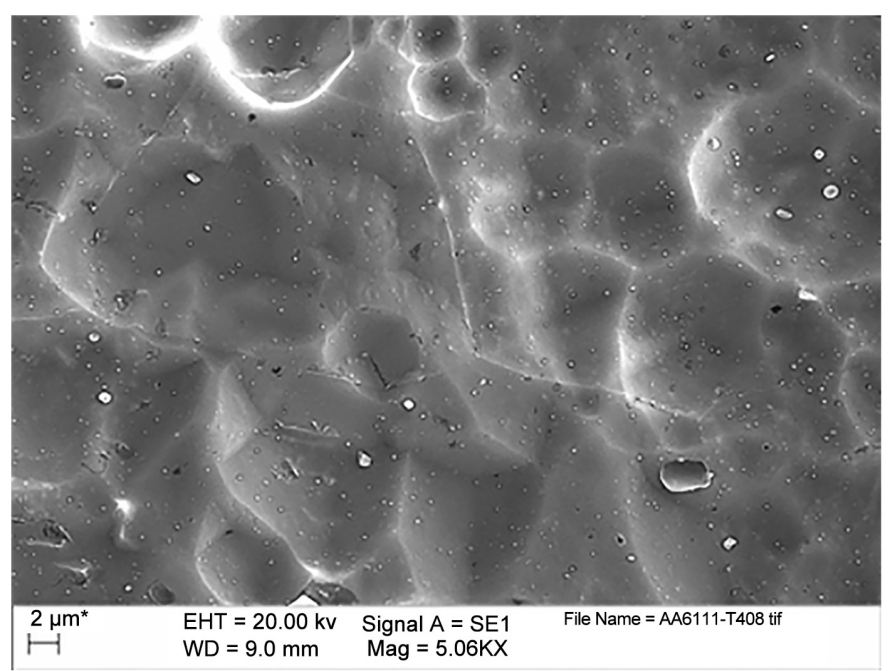

(a)

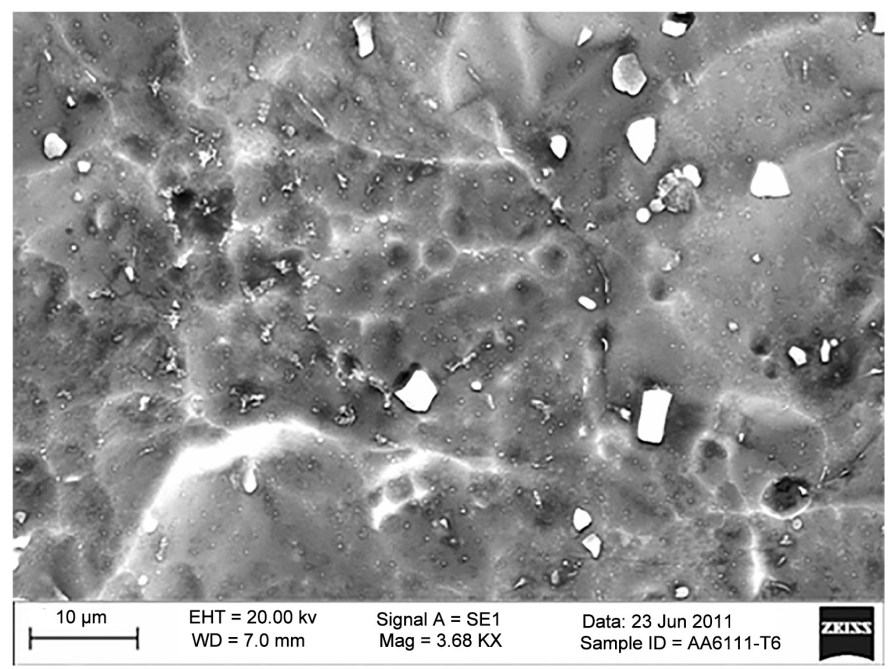

(c)

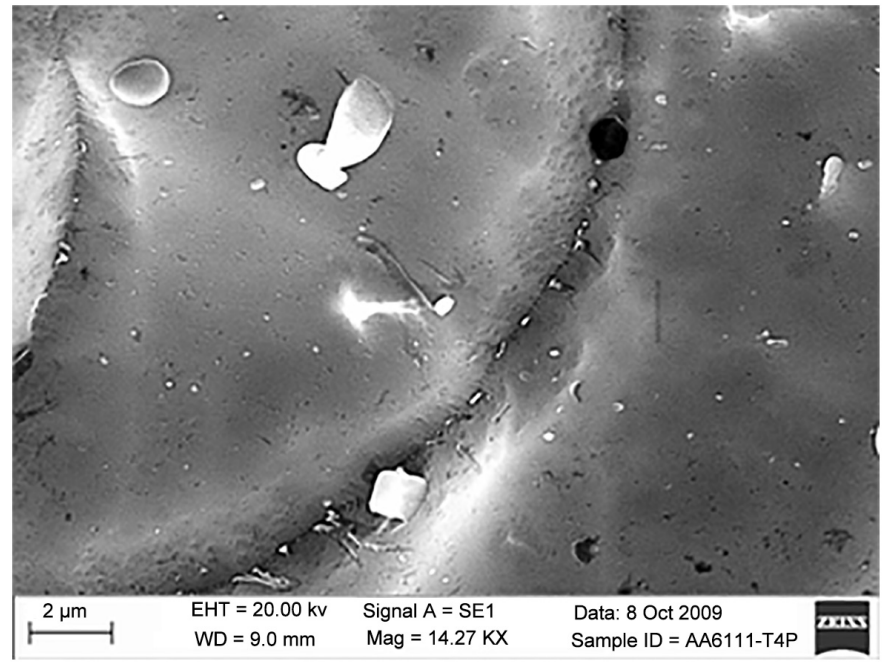

(e)

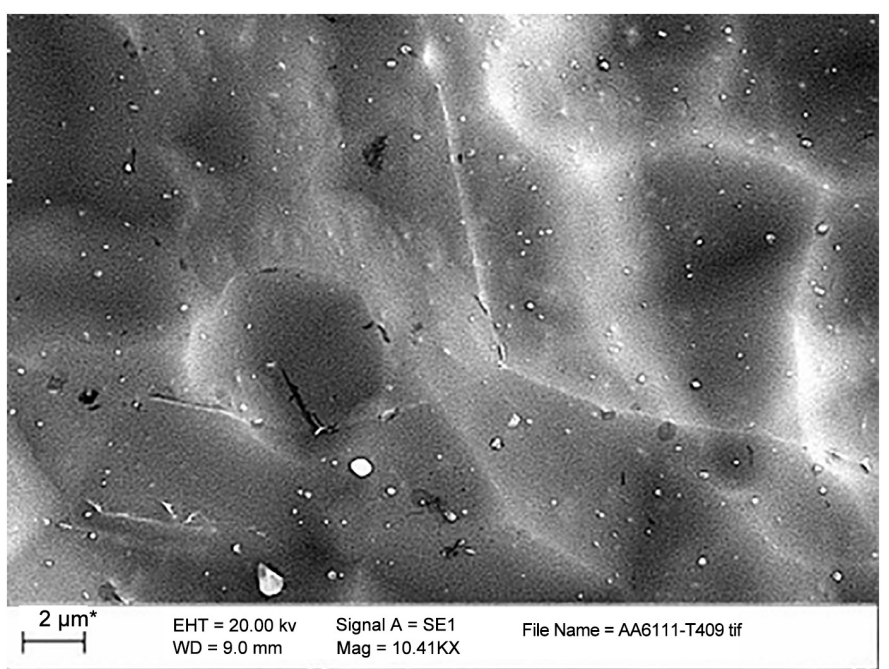

(b)

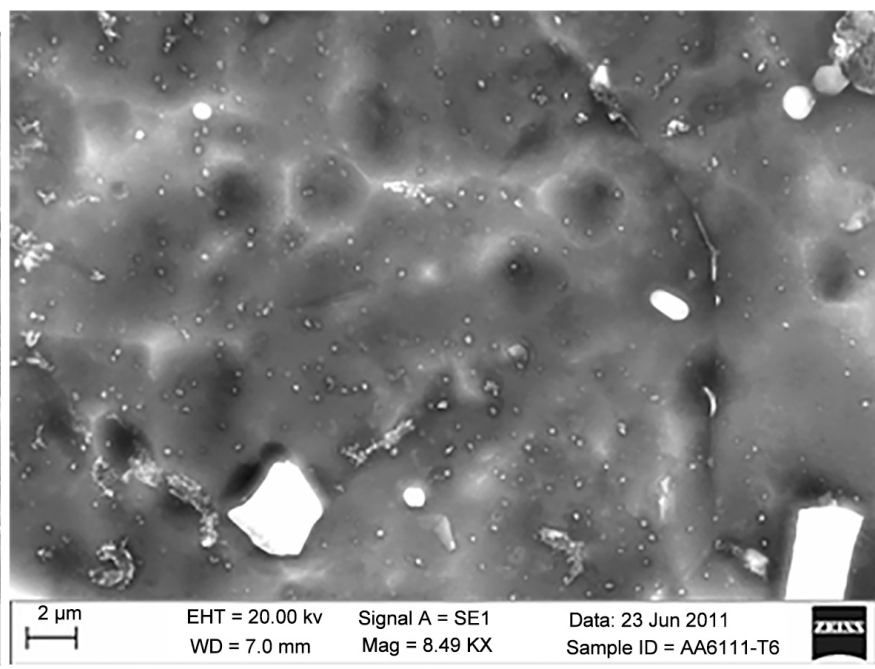

(d)

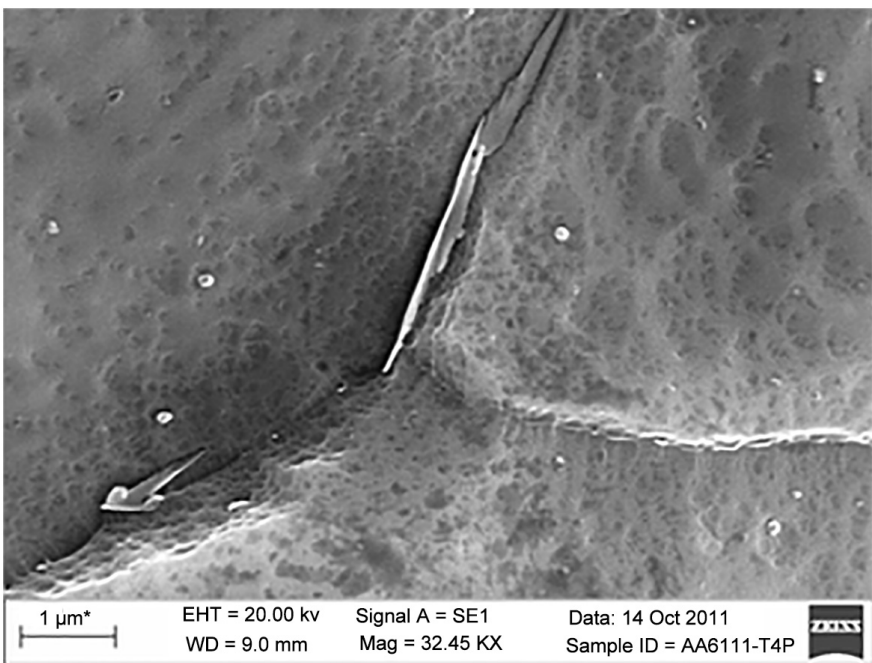

(f) 


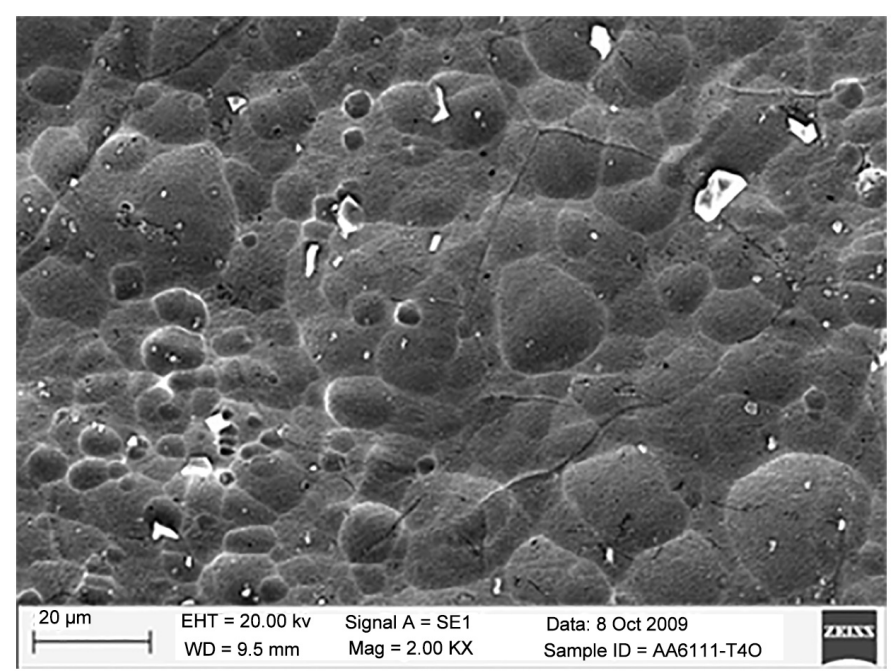

(g)

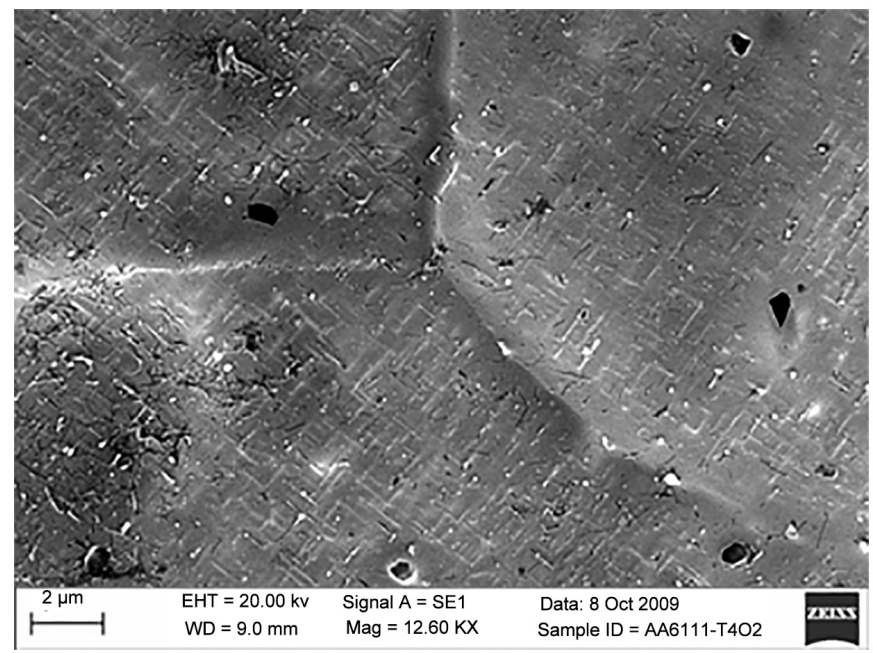

(i)

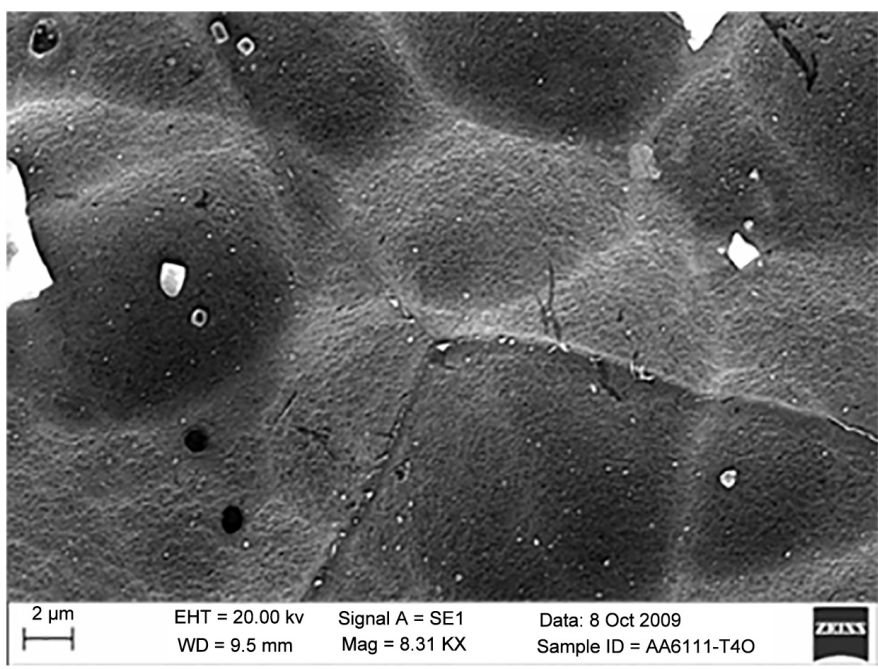

(h)

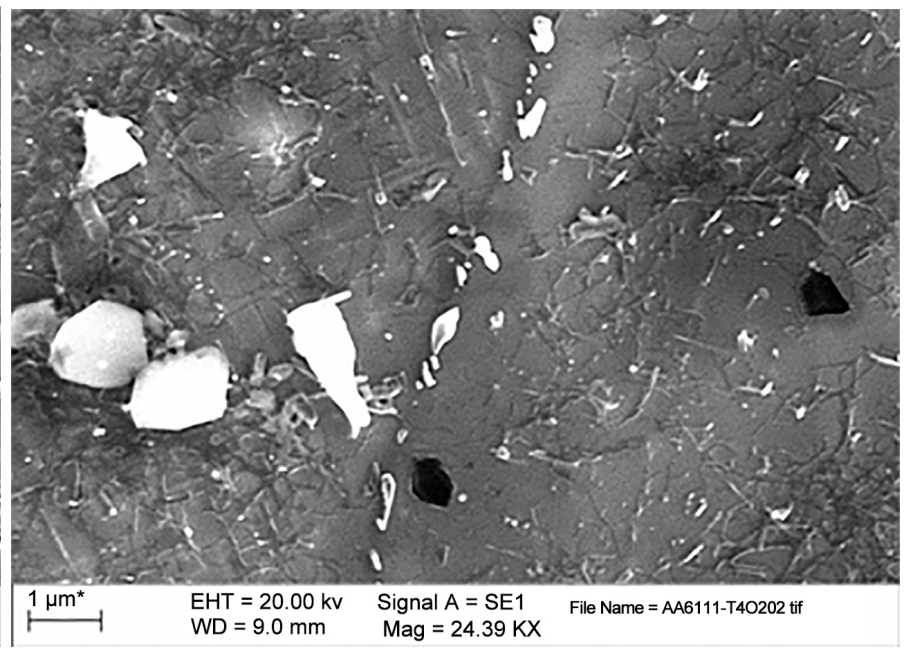

(j)

Figure 6. Scanning electron micrographs of different aging tempers of the AA6111-T4PNA alloy after 300 sec of etching in 10 wt\% NaOH solution at $60^{\circ} \mathrm{C}$ followed by $15 \mathrm{sec}$ room temperature desmutting in 25 vol\% $\mathrm{HNO}_{3}$; (a), (b) as-received, (c), (d) under-aged at $180^{\circ} \mathrm{C}$ for $30 \mathrm{~min}$, (e), (f) peak-aged at $250^{\circ} \mathrm{C}$ for $30 \mathrm{~min}$, (g), (h) over-aged at $310^{\circ} \mathrm{C}$ for $30 \mathrm{~min}$ and (i), (j) highly over-aged at $410^{\circ} \mathrm{C}$ for $30 \mathrm{~min}$.

nously distributed $Q$-phase precipitates in matrix of the lower aged tempers of the AA6111 alloy resulted in non-uniform etching, which increased the alloy surface topography.

Furthermore, the higher cathodic activity of the $Q$-phase precipitates along the grain boundaries of the peak-aged AA6111-ST and AA6111-T4PNA alloys is observed to significantly enhance the dissolution rate of the grain boundary regions. Similar phenomenon has been previously observed up oncaustic etching of the AA6111 alloy [23] and other peak-aged Al-Mg-Si-Cu alloys [24] [25]. According to a previous AFM investigation [26], preferential dissolution of the grain boundary regions can be related to the higher potential difference between the copper-rich, intergranular $Q$-phase precipitates and the adjacent solute-depleted matrix of the peak-aged AA6111 alloy. Conse- 
quently, caustic etching results in a significant roughening and variation in the surface topography of the peak-aged AA6111-ST and AA6111-T4PNA alloys.

\section{Conclusions}

The dissolution rate of the automotive AA6111 alloy during the conventional caustic etching and acidic desmutting surface pre-treatments increases with the alloy preaging condition. This is related to the precipitation of the cathodic Q-phase and the depletion of the alloy solid solution in magnesium and silicon.

The surface topography induced by caustic etching and acidic desmutting surface pre-treatment of AA6111 alloy is strongly dependant on distribution and the electrochemical activity of the $Q$-phase precipitates. The homogenous distribution of the $Q$ phase precipitate in the matrix of the highly over-aged AA6111 alloy results in a more uniform etching of the alloy in sodium hydroxide solution, whereas the less homogenously distributed $Q$-phase precipitates in the matrix of the lower aged tempers increases the alloy surface topography. This reveals the importance of the caustic etching procedure prior to paint application of the AA6111 body panels in the automotive industry, which may cause a significant variation in the surface roughening and, thus, the reflectivity in the vicinity of the panels welding joints.

\section{Limitations of the Study}

It to be mentioned that, due to the lack of sufficient time, the investigation method employed in the present work was limited to SEM. However, other surface characterization techniques, such as AFM or Profilometer can be also utilized to study the surface topography of caustic etched AA6111 alloy.

\section{Acknowledgements}

The authors gratefully acknowledge the EPSRC LATEST 2Programme Grant (EP/ H020047/1) for the financial support of this work.

\section{References}

[1] Cain, R.J. (2006) Aqueous Processing of Corrosion Inhibiting Hybrid Nanocomposite Bulk Coating. MSc Thesis, The University of Cincinnati.

[2] Ghosh, S. (2007) Effect of Stress on Initiation and Propagation of Localized Corrosion in Alumiumum Alloys. Ph.D. Thesis, School of Engineering, University of Birmingham.

[3] Spoelstra, M. (2000) Filiform Corrosion of Anodised Aluminium Alloys. Ph.D. Thesis, Delft University of Technology.

[4] Premendra (2007) Investigation of Surface Layer on Rolled Recycled AA5050 in Relation to Filiform Corrosion. Ph.D. Thesis, Delft University of Technology.

[5] Buytaert, G., Kernig, B., Brinkman, H. and Terryn, H. (2006) Influence of Surface PreTreatments on Disturbed Rolled-In Subsurface Layers of Aluminium Alloys. Surface \& Coatings Technology, 201, 2587-2598. http://dx.doi.org/10.1016/j.surfcoat.2006.05.004

[6] Thompson, G.E. (2006) The Role of Alloying Elements on the Surface Treatment and Fin- 
ishing of Aluminium. Materials Science Forum, 519-521, 615-620.

http://dx.doi.org/10.4028/www.scientific.net/MSF.519-521.615

[7] Trueba, M. and Trasatti, S. (2010) Study of Al Alloy Corrosion in Neutral NaCl by the Pitting Scan Technique. Materials Chemistry and Physics, 121, 523-533.

http://dx.doi.org/10.1016/j.matchemphys.2010.02.022

[8] Koroleva, E., Thompson, G., Hollrigl, G. and Bloeck, M. (1999) Surface Morphological Changes of Aluminium Alloys in Alkaline Solution: Effect of Second Phase Material. Corrosion Science, 41, 1475-1495. http://dx.doi.org/10.1016/S0010-938X(98)00188-7

[9] Lunder, O., Olsen, B. and Nisancioglu, K. (2002) Pre-Treatment of AA6060 Aluminium Alloy for Adhesive Bonding. International Journal of Adhesion and Adhesives, 22, 143-150. http://dx.doi.org/10.1016/S0143-7496(01)00049-5

[10] Lunder, O. (2003) Chromate-Free Pre-Treatment of Aluminium for Adhesive Bonding. Ph.D. Thesis, Norwegian University of Science and Technology.

[11] Liu, Y., Skeldon, P., Thompson, G., Habazaki, H. and Shimizu, K. (2002) Anodic Film Growth on an Al-21at.\%Mg Alloy. Corrosion Science, 44, 1133-1142. http://dx.doi.org/10.1016/S0010-938X(01)00115-9

[12] Tsangaraki-Kaplanoglou, I., Theohari, S., Dimogerontakis, T., Wang, Y., Kuo, H. and Kia, S. (2006) Effect of Alloy Types on the Anodizing Process of Aluminium. Surface \& Coatings Technology, 200, 2634-2641. http://dx.doi.org/10.1016/j.surfcoat.2005.07.065

[13] Dahlstrøm, M. (2012) Effect of Copper Content on Etching Response of Aluminium in Alkaline and Acid Solutions. MSc Thesis, Norwegian University of Science and Technology.

[14] Abouarkoub, A., Thompson, G.E., Zhou, X., Hashimoto, T. and Scamans, G. (2015) The Influence of Prolonged Natural Aging on the Subsequent Artificial Aging Response of the AA6111 Automotive Alloy. Metallurgical and Materials Transactions, 46A, 4380-4393.

[15] Nisancioglu, K., Davanger, K., Strandmyr, O. and Holtan, H. (1981) Cathodic Behavior of Impure Aluminum in Aqueous Media. Journal of the Electrochemical Society, 128, 15231526. http://dx.doi.org/10.1149/1.2127675

[16] Guminsky, R., Sheasby, P. and Lamb, H. (1968) Reaction Rates of Second Phase Constituents in Aluminium during Etching, Brightening and Oxalic Acid Anodizing. Transaction of the Institute of Metal Finishing, 46, 44-48.

[17] Short, E. and Sheasby, P. (1969) Reaction of Second Phase Constituents in Aluminium during Etching in Sodium Hydroxide Based Solutions. Transactions of the Institute of Metal Finishing, 47, 27-30.

[18] Shaw, B.A. Corrosion Resistance of Magnesium Alloys. ASM Handbook, Vol. 13A, Pennsylvania State University, 692-696.

[19] Hughes, A., Nelson, K. and Miller, P. (1999) Desmutting of Aluminium Alloy 2024-T3 Using Rare Earth Electrolyte. Materials Science and Technology, 15, 1124-1132. http://dx.doi.org/10.1179/026708399101505167

[20] Birbilis, N. and Buchheit, R. (2008) Investigation and Discussion of Characteristics for Intermetallic Phases Common to Aluminium Alloys as a Function of Solution pH. Journal of the Electrochemical Society, 155, C117-C126.

[21] Wang, X., Poole, W., Esmaeili, S., Lloyd, D. and Embury, J. (2003) Precipitation Strengthening of the Aluminum Alloy AA6111. Metallurgical and Materials Transactions, 34A, 2913-2924. http://dx.doi.org/10.1007/s11661-003-0191-0

[22] Abou Khatwa, M. and Malakhov, D. (2006) On the Thermodynamic Stability of Intermetallic Phases in the AA6111 Aluminum Alloy. Computer Coupling of Phase Diagrams and Ther- 
mochemistry, 30, 159-170. http://dx.doi.org/10.1016/j.calphad.2005.09.001

[23] Roeth, F. (2008) Influence of Near-Surface Structure on Performance of 6000 Series Aluminium Alloys. Ph.D. Thesis, The University of Manchester.

[24] Larsen, M., Walmsley, J., Lunder, O. and Nisancioglu, K. (2010) Effect of Excess Silicon and Small Copper Content on Intergranular Corrosion of 6000-Series Aluminum Alloys. Journal of the Electrochemical Society, 157, C61-C68. http://dx.doi.org/10.1149/1.3261804

[25] Lunder, O., Walmsley, J., Mack, P. and Nisancioglu, K. (2005) Formation and Characterisation of a Chromate Conversion Coating on AA6060 Aluminium. Corrosion Science, 47, 1604-1624. http://dx.doi.org/10.1016/j.corsci.2004.08.012

[26] Abouarkoub, A. (2012) Microstructure Characterization and Corrosion Properties of the Heat Affected Zones of the Welded Automotive AA6111 Alloys. Ph.D. Thesis, School of Materials, University of Manchester.

\section{Submit or recommend next manuscript to SCIRP and we will provide best service} for you:

Accepting pre-submission inquiries through Email, Facebook, LinkedIn, Twitter, etc.

A wide selection of journals (inclusive of 9 subjects, more than 200 journals)

Providing 24-hour high-quality service

User-friendly online submission system

Fair and swift peer-review system

Efficient typesetting and proofreading procedure

Display of the result of downloads and visits, as well as the number of cited articles

Maximum dissemination of your research work

Submit your manuscript at: http://papersubmission.scirp.org/

Or contact jmmce@scirp.org 